\title{
Effect of a rat uterine fluid endopeptidase on lysis of the zona pellucida
}

\author{
M. G. Rosenfeld* and M. S. Joshi $\dagger$ \\ Department of Anatomy/Cell Biology, Downstate Medical Center, Brooklyn, New York 11203, \\ and †Department of Anatomy, University of North Dakota, Grand Forks, North Dakota 58201, \\ U.S.A.
}

\begin{abstract}
Summary. The uterine endopeptidase of rats caused lysis of the zona pellucida of unfertilized rat and mouse eggs but not of fertilized rat and mouse eggs. Induction of cortical granule discharge of unfertilized eggs by treatment with boromycin and a guanidine derivative led to resistance of the zona pellucida to lysis by the endopeptidase. Lysis of the hamster zona pellucida occurred within $90 \mathrm{~min}$, whatever the treatment and trypsin caused lysis of all zonae within $20 \mathrm{~min}$. We suggest that after fertilization cortical granule discharge modifies the zona pellucida to prevent digestion by the endopeptidase.
\end{abstract}

\section{Introduction}

The origin of the substance responsible for zona lysis has been the subject of considerable controversy. In the mouse, a zona lysin of uterine origin has been suggested as being responsible for the loss of the zona pellucida from unfertilized eggs (McLaren, 1970; Mintz, 1970), morulae of the lethal genotype $t^{12} / t^{12}$ (Mintz, 1964) and blastocysts (McLaren, 1970; Mintz, 1970). In addition to its role in zona lysis, this uterine lysin may act as an implantation-initiating factor, possibly by changing glycoprotein or other molecules on the surface of the blastocyst cells and making the surfaces more adhesive to the uterine wall (Mintz, 1970).

Dickmann (1969) proposed that zona lysis in the rat was dependent upon trophoblastic maturation since late blastocysts lost the zona pellucida sooner than did early blastocysts or morulae when transferred to pseudopregnant recipients (Dickmann \& Noyes, 1960; Dickmann \& DeFeo, 1967). However, a more comprehensive study by Surani (1975) suggested that lysis was due to an oestrogen-dependent maternal factor. An oestrogen-dependent rat uterine endopeptidase of maternal origin has been described (Joshi, Yaron \& Lindner, 1970; Joshi \& Murray, 1974; Joshi \& Rosenfeld, 1976) and this protein may play a role in the implantation process (Rosenfeld \& Joshi, 1977). Since the endopeptidase is present in the uterus at the time of implantation (Joshi \& Murray, 1974) and loss of zona pellucida is a prerequisite for normal implantation in the rat, the possibility that this protein may act as a zona lysin was examined.

\section{Materials and Methods}

Wistar rats (Carworth Farms), Swiss mice (The Jackson Laboratory) and hamsters (Carworth Farms) were maintained in a temperature-controlled environment $\left(22 \pm 1^{\circ} \mathrm{C}\right)$ with $14 \mathrm{~h}$ light $(6: 00-2: 00 \mathrm{~h}) /$ day. Purina lab chow and tap water were freely available. U.S.A.

* Present address: N.Y.U. Medical Center, Department of Cell Biology, 550 First Avenue, New York 10016, 
The uterine endopeptidase was isolated and purified from rat luminal fluid by the method described by Joshi et al. (1970). The protein content of the purified enzyme was measured by the procedure of Lowry, Rosebrough, Farr \& Randall (1951), using bovine serum albumin (BSA) as the standard.

\section{Experiment 1}

The zona lytic effect of the rat uterine endopeptidase on unfertilized rat, mouse and hamster eggs was studied in vitro. To see if there was some specificity based on the nature of the amino acids to be cleaved in the zona, eggs were also treated with the non-uterine peptidase, trypsin, which is known to cause lysis of the zona pellucida (Chang \& Hunt, 1956).

Immature female rats (22-25 days) were induced to superovulate by injection of PMSG and hCG as described previously (Rosenfeld \& Joshi, 1977). Superovulation was induced in 60-day-old C57BL/6J mice by the procedure of Rugh (1968) and in 6-8-week-old hamsters by the procedure of Gwatkin, Rasmusson \& Williams (1976). The animals were killed by cervical dislocation $12-18 \mathrm{~h}$ after the hCG injection and the ampullae were removed and placed in a large depression slide containing a modified Krebs-Ringer-bicarbonate solution (Toyoda \& Chang, 1974). The eggs in cumulus mass were dissected out of the ampullae and $1 \mathrm{ml}$ of a solution of $0.1 \%$ hyaluronidase containing $0.1 \%(\mathrm{w} / \mathrm{v}) \mathrm{BSA}$ was added to remove the cumulus cells. After washing, the cumulus-free eggs were divided into 4 groups ( $\sim 50 /$ group) and placed in depression slides containing $0.2 \mathrm{ml}$ incubation medium; i.e. modified Krebs-Ringer-bicarbonate and (1) 30 $\mu \mathrm{g}$ purified rat uterine endopeptidase, (2) $30 \mu \mathrm{g}$ boiled purified rat uterine endopeptidase, (3) incubation medium alone or (4) $0.1 \%$ trypsin.

The depression slides were placed in a $\mathrm{CO}_{2}$ incubator at $37^{\circ} \mathrm{C}$ under an atmosphere of $5 \%$ $\mathrm{CO}_{2}$ in air. Samples were removed at hourly intervals by picking the eggs out of the incubation medium with a finely drawn Pasteur pipette. The samples were placed on a glass slide and encircled with petroleum jelly. After being compressed gently with a coverslip, the eggs were examined under a Zeiss phase-contrast microscope for assessment of zona lysis.

\section{Experiment 2}

This experiment tested the zona lytic effect of the rat uterine endopeptidase on fertilized rat, mouse and hamster eggs at various stages of development. For comparison, eggs were also incubated with trypsin.

Female rats (22-25 days), mice (60 days) and hamsters (6-8 weeks) were induced to superovulate as described above, and after the hCG injection they were placed in cages with males of proven fertility. The presence of spermatozoa or a vaginal plug was taken as evidence of a successful mating and designated Day 1. Fertilized 2-cell eggs were obtained by killing animals the following morning (Day 2). The ampullae were removed, placed in a large depression slide containing the incubation medium and processed as above. Morulae and blastocysts were obtained by flushing the oviduct and uterus with incubation media at Days 4 and 5 , respectively.

\section{Experiment 3}

The zona lytic effect of the rat uterine endopeptidase was tested on unfertilized rat, mouse and hamster eggs, obtained as for Exp. 1, by treatment with boromycin or 1,3-bis (4-chlorocinnamylideneamino)guanidine. Both drugs act by altering membrane potential leading to cortical granule discharge (Gwatkin et al., 1976).

Eggs of Group A $(\sim 200)$ were treated with boromycin $(10 \mu \mathrm{g} / \mathrm{ml})$ for $30 \mathrm{~min}$, washed with incubation medium and placed in depression slides containing (1) $0.2 \mathrm{ml}$ incubation medium + 
$30 \mu \mathrm{g}$ purified rat endopeptidase, (2) $0.2 \mathrm{ml}$ incubation medium $+0.1 \%$ trypsin or (3) $0.2 \mathrm{ml}$ incubation medium alone. Eggs of Group B $(\sim 200)$ were treated with the guanidine derivative $(30 \mu \mathrm{g} / \mathrm{ml})$, washed with incubation medium and incubated as described for Group A. Samples were removed at hourly intervals, mounted on glass slides and examined under a phase-contrast microscope.

\section{Results}

\section{Experiment 1}

The results for unfertilized eggs are shown in Text-fig. 1(a) and Pl. 1, Figs 1-3. Zona lysis of rat eggs began about $3 \mathrm{~h}$ after incubation and all eggs were lysed within $5 \mathrm{~h}$. The times for mouse and hamster eggs were $2 \mathrm{~h}$ and $30 \mathrm{~min}$ for the start of lysis and 3 and $1 \frac{1}{2} \mathrm{~h}$ for completion, respectively.

\section{Experiment 2}

As shown in Text-fig. 1(b) fertilized rat and mouse eggs were unaffected by the rat endopeptidase during incubation for 16 (Pl. 1, Figs 4-6) or $24 \mathrm{~h}$ (data not shown). Hamster eggs were again lysed in 30-90 min.

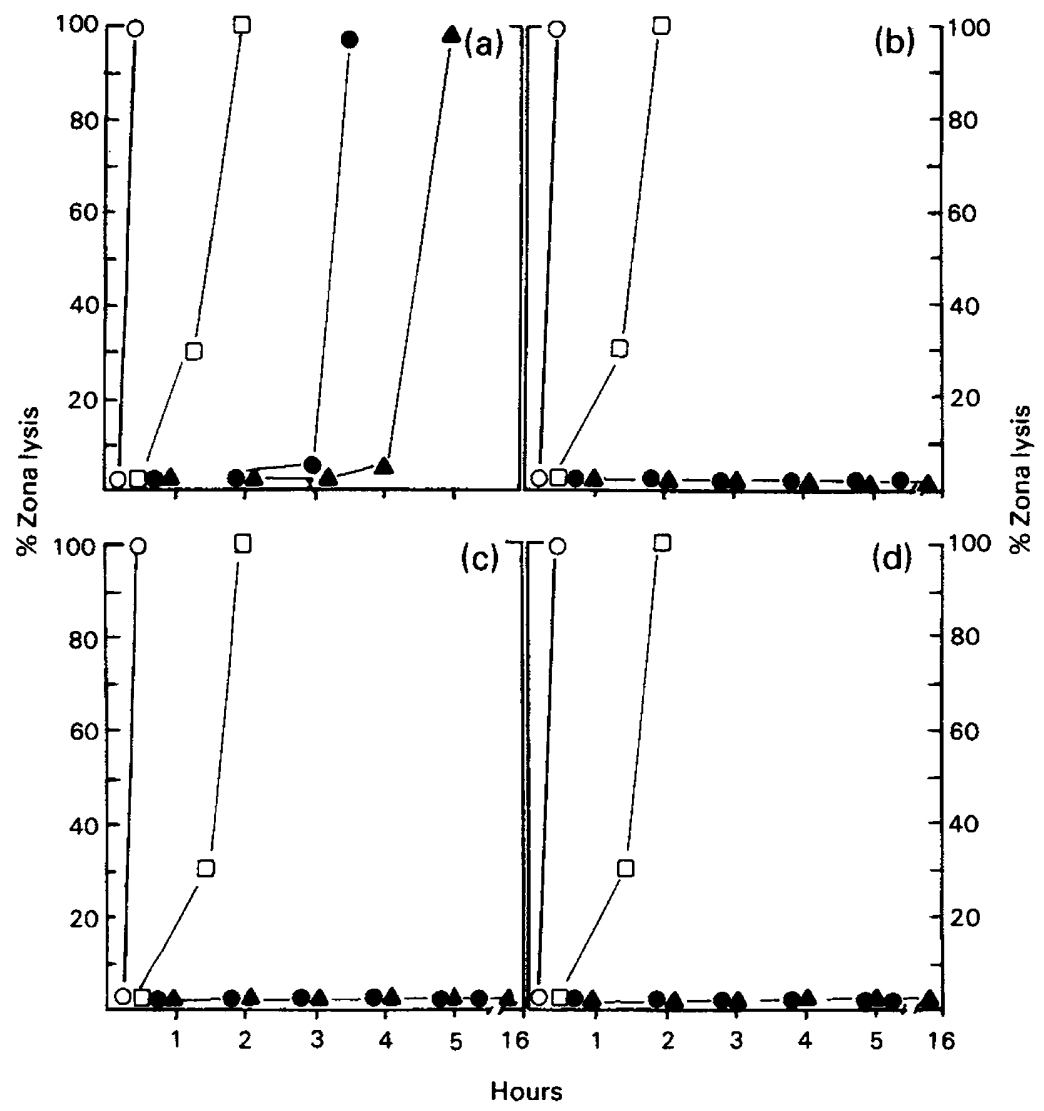

Text-fig. 1. Comparison of lysis times (as \% of eggs completely lysed) of rat ( $(\boldsymbol{\Delta})$, mouse $(\bullet)$ and hamster (ㅁ) zona pellucidas in Exps 1 (a), 2 (b) and 3 (c and d) involving unfertilized (a) and fertilized (b) eggs incubated with endopeptidase, and unfertilized eggs treated with (c) boromycin or (d) a guanidine derivative before addition of endopeptidase. When eggs were incubated with $0 \cdot 1 \%$ trypsin $(O)$, all were lysed within $20 \mathrm{~min}$. 


\section{Experiment 3}

Treatment of unfertilized eggs with boromycin or the guanidine derivative (Text-figs 1c and d) mimicked the result obtained with fertilized eggs; i.e. the zona pellucida of rat and mouse eggs was resistant to proteolytic digestion by the endopeptidase but not by trypsin while that of hamster eggs was quickly lysed (Pl. 1, Figs 7-9).

\section{Discussion}

The results obtained from these experiments lend no positive support for the theory that the rat uterine endopeptidase alone is responsible for lysis of the zona pellucida of fertilized rat eggs. However, this does not preclude the possibility that the endopeptidase is involved in zona lysis by acting in conjunction with other proteins secreted by the uterus and blastocyst at the time of implantation.

The results indicate that the zona pellucida of the rat and mouse is modified during the fertilization process, making it resistant to proteolytic digestion by the endopeptidase. The zona pellucida of fertilized mammalian eggs is known to be resistant to dissolution by proteolytic enzymes and mercaptoethanol and this resistance has been attributed to proteolytic modification of the zona pellucida by cortical granule discharge occurring during the fertilization process (Smithberg, 1953; Chang \& Hunt, 1956; Gwatkin, 1964; Mintz, 1970; Conrad, Buckley \& Stambaugh, 1971; Gould, Zaneveld, Srivastava \& Williams, 1971; Brunner \& Brinster, 1977). Comparison of the results for endopeptidase- and trypsin-treated eggs suggests that there is some specificity in the nature of the amino acids cleaved in the zona by the endopeptidase. The difference of response between the rat and mouse eggs and those of the hamster also indicates that there may be some species specificity in the mode of action of the endopeptidase.

When the cortical granules of unfertilized eggs were discharged by treatment with drugs, rat and mouse eggs became resistant to the action of the rat endopeptidase. Since fertilized eggs also exhibited this marked resistance to the endopeptidase it is assumed that cortical granule discharge is responsible for zona modification in these eggs. This may be an important defence mechanism for fertilized eggs since premature dissolution of the zona by the endopeptidase present in the rat oviduct and uterus (Joshi \& Murray, 1974) would lead to a disruption of normal implantation.

It is entirely possible that the endopeptidase is acting on the same peptide linkages in the zona of fertilized eggs as in unfertilized eggs. However, lysis did not occur in the former because the cortical granule contents modified other proteins in the zona pellucida which are acting to stabilize the structure. This resistance could be related to the cross-linking of the proteins in the zona pellucida caused by an enzyme(s) released from the granules. Evidence for this has come from work on sea urchin eggs which have a vitelline membrane analogous to the mammalian zona pellucida (Epel, 1977; Foerder \& Shapiro, 1977).

\section{PLATE 1}

Figs 1-3. Unfertilized rat, mouse and hamster eggs incubated with the endopeptidase for $4,2 \cdot 5$ and $1 \mathrm{~h}$, respectively. $\times 300$.

Figs 4-6. Fertilized rat, mouse and hamster eggs incubated with endopeptidase for 24,16 and 1 h, respectively. $\times 400$.

Figs 7-9. Unfertilized rat, mouse and hamster eggs pretreated with boromycin (Figs 7 and 9) or guanidine derivative (Fig. 8) were exposed to endopeptidase for 24,16 and $1 \mathrm{~h}$, respectively. $\times 400$. 
PLATE 1
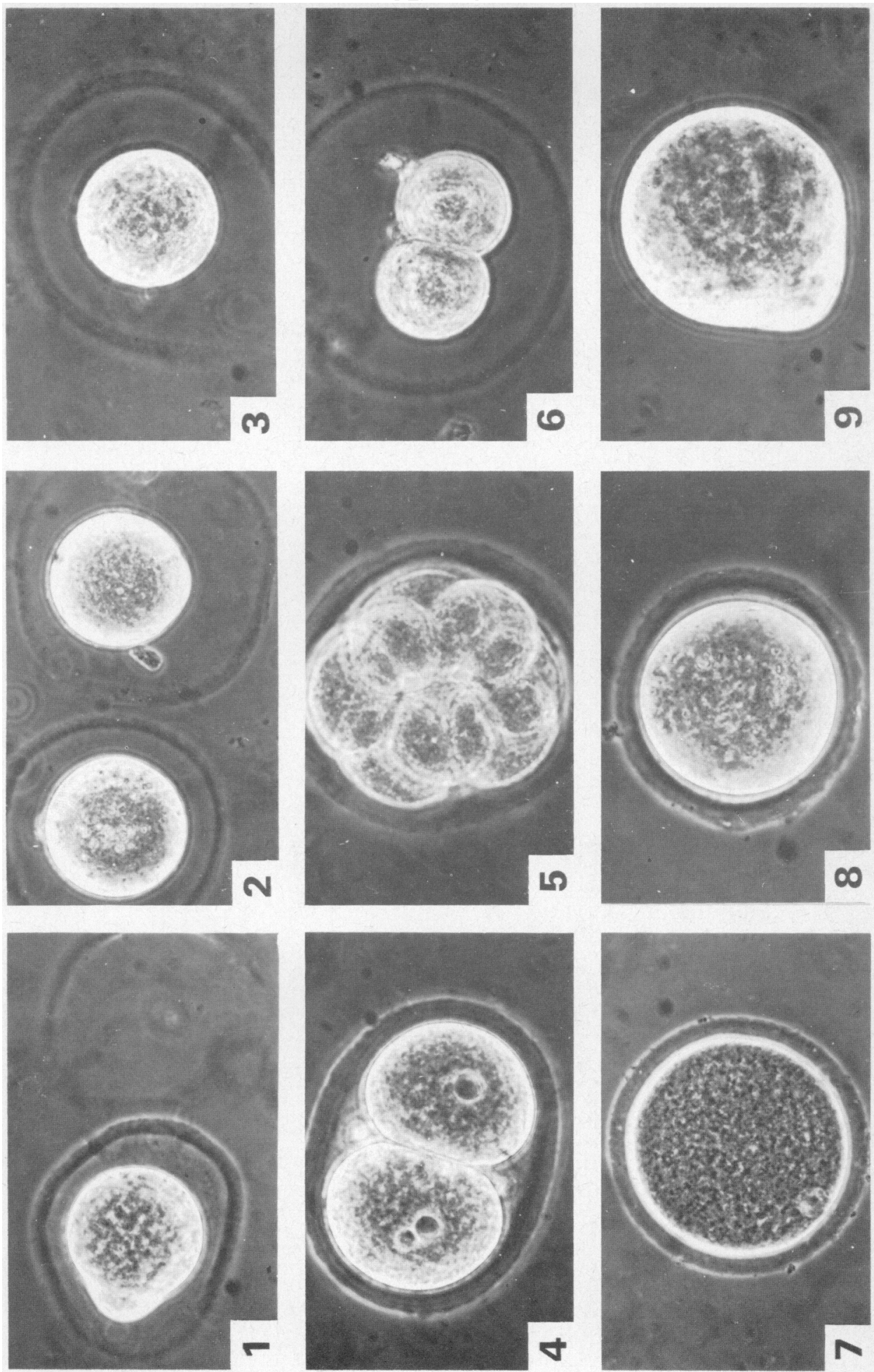

(facing p. 202) 
We thank Mr J. Illari for photographic assistance and Dr R. B. L. Gwatkin of the Merck Institute for providing us with the drugs used.

\section{References}

Brunner, S. \& Brinster, R.L. (1977) Radioiodination of unfertilized and fertilized mouse ova. J. Cell Biol. 75, 61, Abstr.

Chang, M.C. \& Hunt, D.M. (1956) Effects of proteolytic enzymes on the zona pellucida of fertilized and unfertilized mammalian eggs. Expl Cell Res. 11, 497-499.

Conrad, K., Buckley, J. \& Stambaugh, R. (1971) Studies on the nature of the block to polyspermy in rabbit ova. J. Reprod. Fert. 27, 133-135.

Dickmann, Z. (1969) Shedding of the zona pellucida. Adv. Reprod. Physiol. 4, 187-206.

Dickmann, Z. \& DeFeo, V.J. (1967) The rat blastocyst during normal pregnancy and during delayed implantation, including an observation on the shedding of the zona pellucida. J. Reprod. Fert. 13, 3-9.

Dickmann, Z. \& Noyes, R.W. (1960) The fate of ova transferred into the uterus of the rat. J. Reprod. Fert. 1, 197-212.

Epel, D. (1977) The program of fertilization. Sci. Amer. 237, 129-138.

Foerder, C.A. \& Shapiro, B.M. (1977) Release of ovoperoxidase from sea urchin eggs hardens the fertilization membrane with tyrosine crosslinks. Proc. natn. Acad. Sci. U.S.A. 74, 4214-4218.

Gould, K., Zaneveld, L.J.D., Srivastava, P.W. \& Williams, W.L. (1971) Biochemical changes in the zona pellucida of rabbit ova induced by fertilization and sperm enzymes. Proc. Soc. exp. Biol. Med. 136, 6-10.

Gwatkin, R.B.L. (1964) Effect of enzymes and acidity on the zona pellucida of the mouse egg before and after fertilization. J. Reprod. Fert. 7, 99-105.

Gwatkin, R.B.L., Rasmusson, G.H. \& Williams, D.T. (1976) Induction of the cortical reaction in hamster eggs by membrane-active agents. J. Reprod. Fert. 47, 299-303.

Joshi, M.S. \& Murray, I.M. (1974) Immunological studies of the rat uterine fluid peptidase. J. Reprod. Fert. 37, 361-365.
Joshi, M.S. \& Rosenfeld, M.G. (1976) Hormonal influence on the appearance of uterine specific peptidase in the rat and mouse. In Proteins of the Biological Fluids, Vol. 24, pp. 109-112. Ed. H. Peeters. Pergamon, Oxford.

Joshi, M.S., Yaron, A. \& Lindner, H.R. (1970) An endopeptidase in the uterine secretion of the proestrous rat and its relation to sperm decapitating factor. Biochem. Biophys. Res. Commun. 38, 52-56.

Lowry, O.H., Rosebrough, N.J., Farr, A.L. \& Randall, R.J. (1951) Protein measurement with the Folin phenol reagent. J. biol. Chem. 193, 265-275.

McLaren, A. (1970) The fate of the zona pellucida in mice. J. Embryol. exp. Morph. 23, 11-19.

Mintz, B. (1964) Formation of genetically mosaic mouse embryos and early development of "lethal $\left(t^{12}\right)$ $\mathrm{t}^{12}$ )-normal" mosaics. J. exp. Zool. 157, 273-292.

Mintz, B. (1970) Control of embryo implantation and survival. In Intrinsic and Extrinsic Factors in Early Mammalian Development, pp. 317-340. Ed. G. Raspé. Pergamon Press, New York.

Rosenfeld, M.G. \& Joshi, M.S. (1977) A possible role of a specific uterine fluid peptidase in implantation in the rat. J. Reprod. Fert. 51, 137-139.

Rugh, R. (1968) Reproductive systems of adult mice. In The Mouse. Its Reproduction and Development, pp. 32-36. Burgess Publishing Company, Minnesota.

Smithberg, M. (1953) The effect of different proteolytic enzymes on the zona pellucida of mouse ova. Anat. Rec. 117, 554, Abstr.

Surani, M.A.H. (1975) Zona pellucida denudation, blastocyst proliferation and attachment in the rat. $J$. Embryol. exp. Morph. 33, 343-353.

Toyoda, Y. \& Chang, M.C. (1974) Fertilization of rat eggs in vitro by epididymal spermatozoa and the development of eggs following transfer. J. Reprod. Fert. 36, 9-22. 